\title{
Coronary Flow Reserve of the Angiographically Normal Left Anterior Descending Coronary Artery in Patients With Remote Coronary Artery Disease
}

\author{
Francesco Pizzuto, MD, Paolo Voci, MD, PhD, Enrica Mariano, MD, \\ Paolo Emilio Puddu, MD, Patrizia Spedicato, MD, and Francesco Romeo, MD
}

\begin{abstract}
Coronary artery disease (CAD) has been suggested to alter coronary flow reserve (CFR; the ratio between hyperemic and baseline coronary flow velocities) not only in territories supplied by stenotic arteries but also in angiographically normal, remote regions. However, few data exist regarding the left anterior descending (LAD) coronary artery as the normal index artery. The influence of remote CAD on CFR of the angiographically normal LAD was evaluated with transthoracic Doppler ultrasound to measure CFR in the LAD during 90 seconds of venous adenosine infusion (140 $\mu \mathrm{g} / \mathrm{kg} / \mathrm{min}$ ) in 122 subjects who were assigned to 1 group; group 1 comprised 49 controls without angiographically detectable CAD, and group 2 consisted of 73 patients with an angiographically normal LAD and remote CAD. Group 2 was divided into 4 subgroups: 16 patients with previous remote percutaneous coronary intervention (group 2A); 13 patients with significant remote stenosis (group 2B);
\end{abstract}

-xperimental and clinical reports have suggested 3 that acute myocardial infarction decreases coronary flow reserve (CFR; the ratio between hyperemic and baseline flow velocities) not only in the infarctrelated artery but also in remote, angiographically normal coronary arteries. ${ }^{1-5}$ Discordant results have been reported in patients without previous myocardial infarction, ${ }^{6-8}$ and it is unclear what the interaction is when the normal vessel is the left anterior descending (LAD) coronary artery. Recent advances in color Doppler technology have allowed imaging of the distal $\mathrm{LAD}^{9,10}$ by transthoracic echocardiography, thereby opening the way to the noninvasive detection of recanalization in acute anterior myocardial infarction, ${ }^{11}$ diagnosis of LAD disease by measurement of CFR, ${ }^{12-15}$ and monitoring of changes in CFR after stenting. ${ }^{16,17}$ The aim of this study was to assess whether CFR in an angiographically normal LAD is preserved in patients with remote coronary artery disease (CAD), including those with myocardial infarction. CFR was prospectively measured by transthoracic coronary Doppler ultrasound.

\footnotetext{
From the Section of Cardiology, "La Sapienza" University; and the Section of Cardiology, "Tor Vergata" University, Rome, Italy. Manuscript received February 4, 2004; revised manuscript received and accepted May 18, 2004.

Address for reprints: Paolo Voci, MD, Via San Giovanni Eudes, 27, 00163 Rome, Italy. E-mail: voci@uniroma 1.it.
}

23 patients with previous remote myocardial infarction and percutaneous coronary intervention (group 2C); and 21 patients with previous remote myocardial infarction but no percutaneous coronary intervention (group 2D). CFR in the LAD was not significantly different in groups 1 and $2(3.08 \pm 0.61$ and $3.03 \pm 0.69$, respectively, $p$ $=$ NS). Decreased ejection fraction and increased wall motion score index in patients with remote CAD (p $<0.00001$ ) and multivessel CAD did not affect CFR in the LAD (group 2A $3.18 \pm 0.77$; group 2B $3.05 \pm 0.65$; group $2 C 3.07 \pm 0.79$; group $2 D 2.86 \pm 0.50$, respectively; $F=0.63, p=N S)$. In conclusion, CFR of an angiographically normal LAD is preserved in patients with remote $C A D$, even in the presence of previous remote myocardial infarction and wall motion abnormalities. (c)2004 by Excerpta Medica, Inc.

(Am J Cardiol 2004;94:577-582)

\section{METHODS}

Study population: Patients were selected from a population undergoing diagnostic or therapeutic cardiac catheterization at our institution. The requisite to be enrolled in this study was the presence of an angiographically normal LAD with or without remote CAD. From June 2002 to August 2003, 122 consecutive subjects (105 men and 17 women; mean age 58 \pm 10 , range 31 to 77 ) were recruited and assigned to 1 of 2 groups; group 1 comprised 49 controls with chest pain but no angiographically detectable CAD (i.e., coronary arteries with angiographically smooth silhouettes), and group 2 consisted of 73 patients with an angiographically normal LAD and remote CAD. Group 2 was further divided into 4 subgroups: 16 patients with remote percutaneous coronary intervention but no evidence of myocardial infarction (group 2A); 13 patients without remote myocardial infarction but significant $(\geq 70 \%)$ remote coronary stenosis (group 2B); 23 patients with remote myocardial infarction and previous remote percutaneous coronary intervention (group 2C); and 21 patients with remote myocardial infarction but no remote percutaneous coronary intervention (group 2D). Data on hypercholesterolemia (total cholesterol levels $>220 \mathrm{mg} / \mathrm{dl}$ ), hypertension (blood pressure $>140 / 90 \mathrm{~mm} \mathrm{Hg}$ ), diabetes (fasting glycemia $>126 \mathrm{mg} / \mathrm{dl}$ ), active smoking, and left ventricular hypertrophy (thickness of septum and left ventricular free wall $\geq 12 \mathrm{~mm}$ ) were collected. 
Transthoracic coronary Doppler echocardiography: All subjects underwent transthoracic echocardiography and noninvasive Doppler ultrasound assessment of CFR in the LAD 1 to 2 days within diagnostic coronary angiography, $5.58 \pm 2.13$ days (range 2 to 10) after percutaneous coronary intervention, and $37.33 \pm 18.97$ days (range 2 to 70 ) after myocardial infarction. Patients with acute coronary syndromes, congestive heart failure, significant valvular heart diseases, and contraindications to adenosine administration (second- to third-degree atrioventricular block, severe chronic obstructive pulmonary disease, and bronchospasm) were excluded. All subjects were in sinus rhythm, stable condition, and fasting state when CFR was assessed. All coronary active medications were withdrawn the day before the Doppler ultrasound examination. The study was approved by our institutional review committee. All subjects were informed on the purpose and nature of the study and provided written informed consent before participation.

Transthoracic coronary Doppler echocardiography was performed as previously described ${ }^{9,10,15-17}$ with a small multihertz transducer that allowed independent change of frequency between 2-dimensional (3.5 to $7.0 \mathrm{MHz}$ ) and color (3.5 to $6.0 \mathrm{MHz}$ ) Doppler and was connected to an ultrasound system (Sequoia C256, Siemens-Acuson, Mountain View, California). Coronary flow velocity was measured by pulsed Doppler ultrasound under a color-coding guide. The best longaxis view in color flow imaging was obtained to maintain a $<30^{\circ}$ angle between flow and Doppler beams. All studies were continuously recorded on a half-inch VHS videotape for off-line analysis.

End-diastolic and end-systolic volume indexes and ejection fraction were measured by the biplane method of disks. Wall motion score index was calculated using the 16-segment model proposed by the American Society of Echocardiography, ${ }^{18}(1=$ normal, $2=$ hypokinetic, $3=$ akinetic, and $4=$ dyskinetic).

Coronary flow reserve: Each subject underwent Doppler echocardiographic recordings of LAD blood flow velocity at baseline and during 90 seconds of adenosine infusion $(140 \mu \mathrm{g} / \mathrm{kg} / \mathrm{min})$. Heart rate and electrocardiogram were continuously monitored. Blood pressure was recorded at baseline, during adenosine infusion, and at recovery. Peak and mean diastolic flow velocities were measured before and during adenosine infusion. For each test, the 3 highest Doppler velocities were computed and averaged. CFR was calculated by the same operator who performed the test using peak diastolic values and who was blinded to the angiographic data.

Feasibility and reproducibility of CFR assessment: Feasibility of coronary imaging and Doppler ultrasound recordings was evaluated by consensus of 2 experienced observers. Inter- and intraobserver variabilities in measurements of Doppler velocity in our laboratory were $3.2 \%$ and $2 \%$, respectively, ${ }^{16}$ whereas intraindividual variability never exceeded (in absolute average values) $2 \mathrm{~cm} / \mathrm{s}$, thus providing a maximal $\pm 6 \%$ difference in relative terms. ${ }^{16}$
Coronary angiography: Cardiac catheterization was performed in all patients by the percutaneous femoral approach. Coronary lumen diameter was measured online with electronic calipers by 2 expert operators performing angiography who were blinded to the Doppler results. The outer diameter of the fluid-filled diagnostic catheter, which was centered, was used as a scaling device to obtain absolute arterial dimensions. Two orthogonal projections of the coronary artery lesion at end-diastole were used to measure coronary stenosis, and percent diameter stenosis was derived from the angiographic view best depicting the narrowing. In this study, stenosis $\geq 70 \%$ was considered significant.

Statistical analysis: Data are expressed as mean \pm SD except for data expressed as percent or proportion, where \pm SE were used. One-way analysis of variance using Bonferroni's correction to assess intergroup differences (BMDP-7D, University of California Press, Berkeley, California) was used to analyze data, and 2-way analysis of variance was used to assess intergroup differences of hemodynamic variables (BMDP$2 \mathrm{~V}$, University of California Press). Confidence intervals $(95 \%)$ were calculated by standard formulas. A p value $<0.05$ was considered statistically significant.

\section{RESULTS}

Patient characteristics: There was, as expected, more severe CAD, lower ejection fractions, and more wall motion abnormalities in group 2 and a higher prevalence of smoking in groups $2 \mathrm{~A}$ and $2 \mathrm{D}$ (Table 1).

Coronary flow reserve: CFRs of the angiographically normal LAD were $3.08 \pm 0.61$ in group 1 and $3.03 \pm 0.69$ in group $2(\mathrm{p}=\mathrm{NS})$. When patients were grouped according to CAD characteristics outside the LAD (previous percutaneous coronary intervention, $\geq 70 \%$ coronary stenosis, and previous myocardial infarction), a slight but nonsignificant decrease of CFR in the LAD was observed only in those with previous myocardial infarction who did not undergo percutaneous coronary intervention (Table 1 and Figure 1). Neither decreased ejection fraction nor a higher wall motion score index affected CFR in the LAD (Table 1). Figure 2 shows a subject with angiographically normal coronary arteries and a CFR of 3.3, and Figures 3 to 5 show patients with angiographically normal LAD and different types of remote CAD. The CFR in the LAD of these patients was always within the range of group 1 (controls), even in the case of recent (Figure 4) or old (Figure 5) remote myocardial infarctions, with or without revascularization of the infarct-related artery. The presence of 1- or 2-vessel CAD did not influence CFR in the LAD ( $F=0.15, p$ $=\mathrm{NS}$ ) when all patients with remote $\mathrm{CAD}$ were analyzed and when patients with previous remote myocardial infarction were excluded $(\mathrm{F}=2.17, \mathrm{p}=$ NS).

Hemodynamic variables: Adenosine infusion induced similar changes in all groups (2-way analysis of variance interaction term, $p=0.13$ and 0.59 in groups 1 and 2, respectively) with respect to heart rate, which increased $(\mathrm{p}<0.0001)$, and mean arterial pressure, 
TABLE 1 Study Population, Risk Factors, and Hemodynamic Data

\begin{tabular}{|c|c|c|c|c|c|c|}
\hline Variable & $\begin{array}{l}\text { Group } 1 \\
(n=49)\end{array}$ & $\begin{array}{l}\text { Group 2A } \\
(n=16)\end{array}$ & $\begin{array}{l}\text { Group 2B } \\
(n=13)\end{array}$ & $\begin{array}{l}\text { Group 2C } \\
(n=23)\end{array}$ & $\begin{array}{l}\text { Group 2D } \\
(\mathrm{n}=21)\end{array}$ & F (p Value) \\
\hline Age (ys) & $60 \pm 11$ & $56 \pm 12$ & $54 \pm 8$ & $56 \pm 6$ & $58 \pm 9$ & 1.20 (NS) \\
\hline $\begin{array}{l}\text { Sex }(0=\text { women; } \\
1=\text { men })\end{array}$ & $0.73 \pm 0.06$ & $0.94 \pm 0.06$ & $0.84 \pm 0.10$ & $1.00 \pm 0$ & $1.00 \pm 0$ & $4.13(<0.036)^{*}$ \\
\hline Body surface area $\left(\mathrm{m}^{2}\right)$ & $1.84 \pm 0.15$ & $1.85 \pm 0.18$ & $1.85 \pm 0.16$ & $1.89 \pm 0.11$ & $1.88 \pm 0.14$ & 0.48 (NS) \\
\hline $\begin{array}{l}\text { Hypercholesterolemia (>220 } \\
\mathrm{mg} / \mathrm{L} \text { ) }\end{array}$ & $0.59 \pm 0.07$ & $0.69 \pm 0.12$ & $0.69 \pm 0.10$ & $0.69 \pm 0.10$ & $0.62 \pm 0.10$ & 0.28 (NS) \\
\hline Diabetes mellitus & $0.16 \pm 0.05$ & $0.06 \pm 0.06$ & $0.23 \pm 0.12$ & $0.30 \pm 0.10$ & $0.19 \pm 0.09$ & 1.00 (NS) \\
\hline Hypertension & $0.53 \pm 0.07$ & $0.62 \pm 0.12$ & $0.54 \pm 0.14$ & $0.48 \pm 0.11$ & $0.76 \pm 0.09$ & 1.12 (NS) \\
\hline Smoking habits & $0.49 \pm 0.07$ & $0.87 \pm 0.08$ & $0.46 \pm 0.14$ & $0.70 \pm 0.10$ & $0.76 \pm 0.09$ & $3.11<0.018)^{\dagger}$ \\
\hline Left ventricular hypertrophy & $0.20 \pm 0.06$ & 0 & $0.15 \pm 0.10$ & 0 & $0.14 \pm 0.08$ & 2.23 (NS) \\
\hline Heart rate (beats $/ \mathrm{min}$ ) & $68 \pm 11$ & $64 \pm 12$ & $64 \pm 11$ & $66 \pm 9$ & $62 \pm 8$ & 1.08 (NS) \\
\hline $\begin{array}{l}\text { Mean arterial blood pressure } \\
\qquad(\mathrm{mm} \mathrm{Hg})\end{array}$ & $97 \pm 8$ & $99 \pm 10$ & $100 \pm 10$ & $100 \pm 9$ & $102 \pm 8$ & 0.82 (NS) \\
\hline Peak flow velocity $(\mathrm{cm} / \mathrm{s})$ & $23 \pm 7$ & $22 \pm 6$ & $25 \pm 6$ & $21 \pm 6$ & $25 \pm 7$ & 1.33 (NS) \\
\hline Ejection fraction $(\%)$ & $64 \pm 0.4$ & $61 \pm 1$ & $60 \pm 0.6$ & $53 \pm 1$ & $50 \pm 1$ & $60.57(<0.00001)^{\S}$ \\
\hline Wall motion score index & $1.01 \pm 0.04$ & $1.07 \pm 0.20$ & $1.02 \pm 0.07$ & $1.30 \pm 0.17$ & $1.40 \pm 0.3$ & $32.55(<0.00001)^{\ddagger}$ \\
\hline Peak LAD CFR & $3.08 \pm 0.61$ & $3.18 \pm 0.77$ & $3.05 \pm 0.65$ & $3.07 \pm 0.79$ & $2.86 \pm 0.50$ & 0.63 (NS) \\
\hline Mean LAD CFR & $2.97 \pm 0.60$ & $3.18 \pm 1.01$ & $2.93 \pm 0.70$ & $2.93 \pm 0.80$ & $2.73 \pm 0.53$ & 0.95 (NS) \\
\hline \multicolumn{7}{|c|}{$\begin{array}{l}\text { One-factor analysis of variance was used to test significance. } F \text { statistics (and corresponding } p \text { values) are shown. In the presence of a significant }(p<0.05) F \text {, } \\
\text { pairwise comparisons were performed using Bonferroni's correction. } \\
{ }^{*} p<0.05 \text {, group } 1 \text { versus groups } 2 C \text { and } 2 D, p=N S \text { in remaining comparisons. } \\
{ }_{t} p<0.10 \text {, group } 1 \text { versus group } 2 A \text {, only. } \\
{ }^{8} p<0.01 \text {, group } 1 \text { versus groups } 2 B, 2 C \text {, and } 2 D \text {, group } 2 A \text { versus groups } 2 C \text { and } 2 D \text {, group } 2 B \text { versus groups } 2 C \text { and } 2 D \text {; and } p<0.05 \text {, group } 2 C \text { versus group } \\
2 D \text {. } \\
{ }^{\ddagger} p<0.01 \text {, group } 1 \text { versus groups } 2 C \text { and } 2 D \text {, group } 2 A \text { versus groups } 2 C \text { and } 2 D \text {, group } 2 B \text { versus groups } 2 C \text { and } 2 D \text { only. }\end{array}$} \\
\hline
\end{tabular}

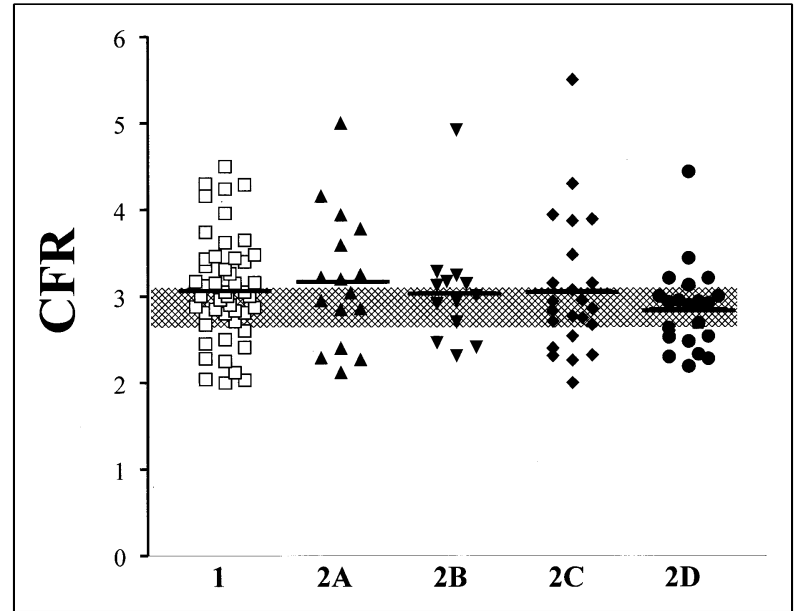

FIGURE 1. CFR is shown individually in control subjects (group 1) and patients with angiographically normal LAD coronary arteries and different types of remote ischemic heart disease (groups $2 A$, 2B, 2C, and 2D). Confidence intervals of the average value obtained in control subjects without risk factors ( $n=7$, CFR $2.95 \pm$ $0.24,95 \%$ confidence interval 2.77 to 3.13 ) are indicated by shading to provide a direct comparison with visually estimates of how CFR distributes according to the groups considered. Thick lines represent average values in each subgroup, none of which lies distant from the distribution of control subjects, considered overall or as those without risk factors (see Results and Discussion for further details).

which decreased $(\mathrm{p}<0.0001)$. Rate-pressure product slightly decreased during adenosine infusion compared with baseline values $(\mathrm{p}<0.02)$. However, groups behaved moderately differently, and the 2-way analysis of variance interaction term showed borderline significance $(\mathrm{p}<0.06)$.

\section{DISCUSSION}

This quite large study shows that remote CAD, in its different forms, including myocardial infarction, has no significant influence over CFR of an angiographically normal LAD. The mean value of $3.03 \pm$ 0.69 found in group 2 (all patients with remote CAD) was largely above the proposed cut-off values of $2.5^{19}$ and $2.24,{ }^{20}$ below which a microvascular dysfunction should be considered in the absence of a significant epicardial stenosis.

Acute coronary occlusion may influence dynamics and flow reserve in remote areas not directly involved by the ischemic event, ${ }^{1-5}$ but it is possible that the problem has been overestimated. Uren et $\mathrm{al}^{1}$ used positron emission tomography in 13 patients 1 week after acute myocardial infarction and found an impaired CFR of $1.53 \pm$ 0.36 in non-infarct-related areas, which increased to 2.19 \pm 0.69 at 6 months. This finding conflicts with other reports that used intracoronary Doppler ultrasound during myocardial infarction. ${ }^{21,22}$ Lepper et al ${ }^{21}$ found a CFR of $\geq 1.6$ even in the infarct-related artery immediately after successful primary percutaneous coronary intervention, followed by good reperfusion as assessed by myocardial contrast echocardiography. Neumann et $\mathrm{al}^{22}$ obtained a similar CFR $(1.56 \pm 0.51)$ in the infarctrelated artery after primary percutaneous coronary intervention, which increased to $2.04 \pm 0.65$ at 1 hour and to $2.66 \pm 0.72$ at 2 weeks. Therefore, it is difficult to reconcile these contrasting findings, obtained in few patients and with overlapping confidence intervals, ${ }^{1}$ whereby CFR in the revascularized infarct-related artery returned toward normal values $(2.66 \pm 0.72)$ at 2 weeks, ${ }^{22}$ but in the angiographically normal artery remained low $(2.19 \pm 0.69)$ at 6 months. ${ }^{1}$ If the impaired 


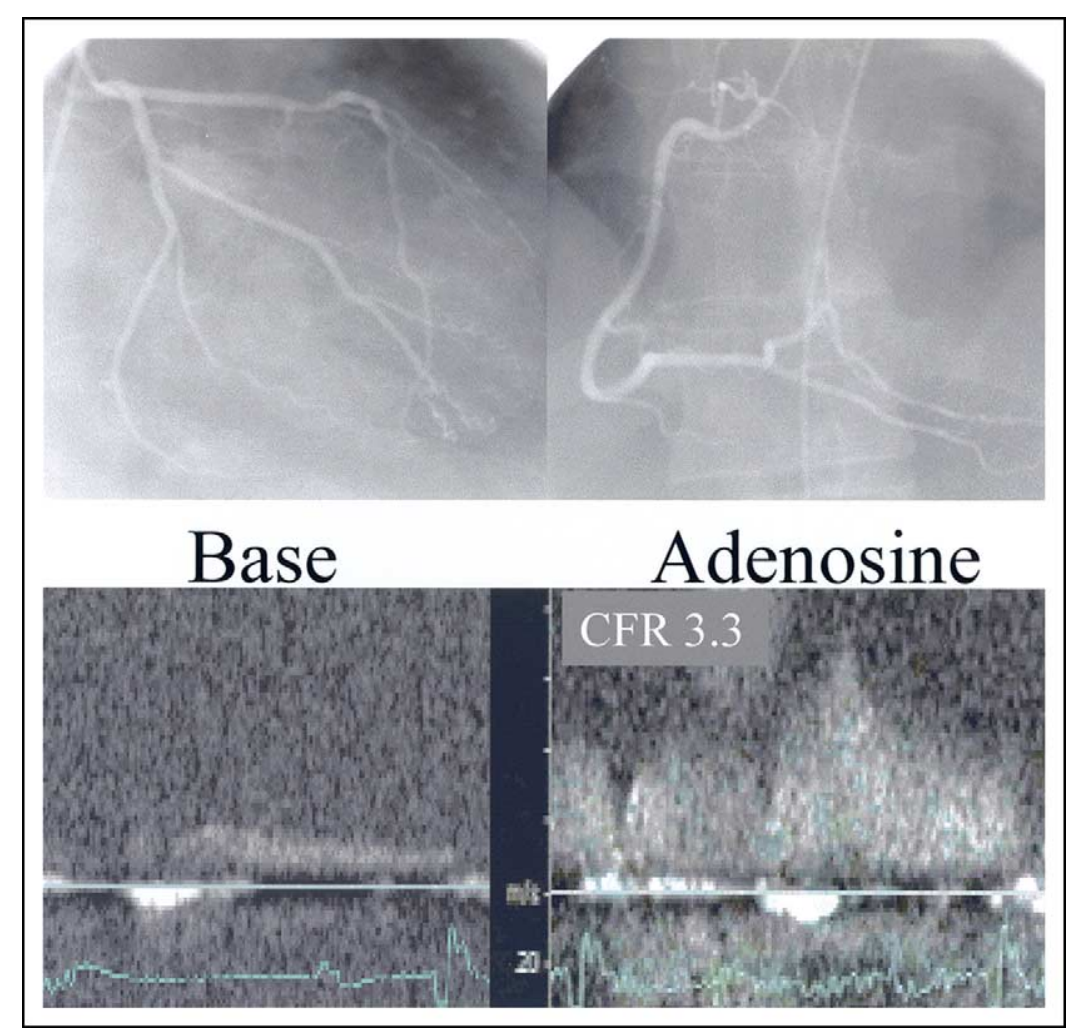

FIGURE 2. (Top) Angiographically normal coronary arteries in a patient in group 1. (Bottom) CFR of the LAD coronary artery, as measured by transthoracic coronary Doppler ultrasound, is 3.3.

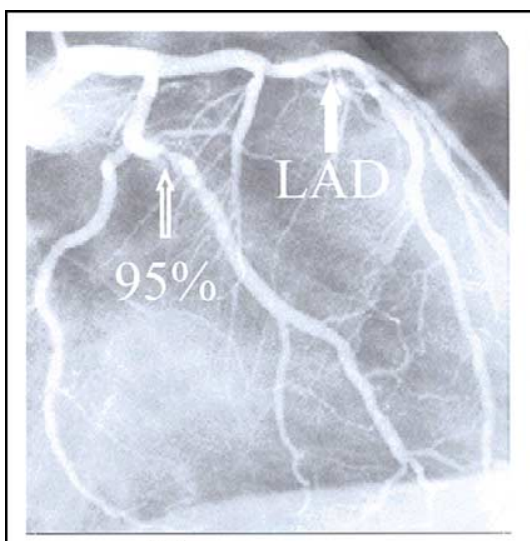

Base

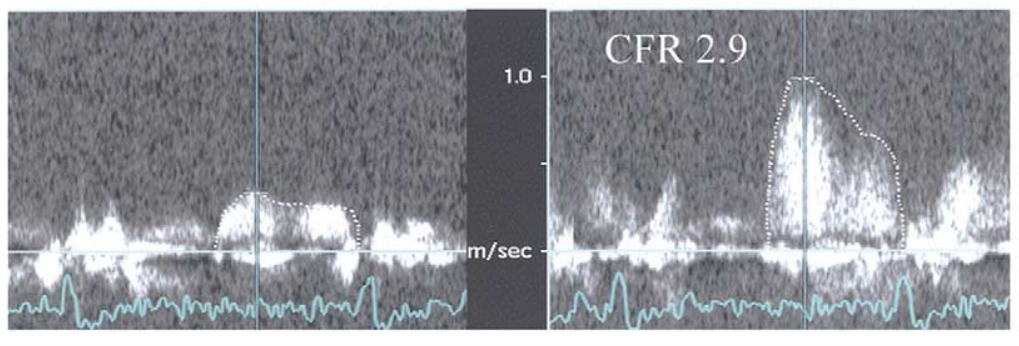

FIGURE 3. (Top) Coronary angiography of a patient in group 2B (angiographically normal LAD and remote significant coronary stenosis) shows $95 \%$ stenosis of the first obtuse marginal branch (open arrow) and $95 \%$ stenosis of the middle tract (solid arrow) of the right coronary artery. (Bottom) CFR of the LAD coronary artery, measured by transthoracic Doppler ultrasound, shows a CFR of 2.9, within the range of the control group. remote CFR is a reality, it should translate into an unusual clinical scenario in which virtually all patients with acute myocardial infarction have symptoms and positive diagnostic tests for remote ischemia before discharge. Of note, $\mathrm{Si}$ cari et al ${ }^{23}$ found remote ischemia in only 96 of 778 patients $(10 \%)$ who underwent dobutamine stress echocardiography $12 \pm 5$ days after myocardial infarction.

Other factors may influence remote flow in acute myocardial infarction, namely: (1) the culprit artery (right and/or circumflex coronary artery affects LAD flow less than the reverse ${ }^{4}$ ), (2) wall motion abnormalities of the jeopardized myocardium, ${ }^{4}$ (3) tight stenosis of the culprit artery, ${ }^{4}(4)$ the time elapsed between the acute event and flow assessment, ${ }^{5}$ and (5) the reopening of the culprit artery. ${ }^{24}$ In our experience, only wall motion abnormalities and the reopening of the culprit artery had a slight but nonsignificant influence (Table 1).

An impaired CFR in an angiographically normal coronary artery has been described in small series of patients with stable remote CAD without previous myocardial infarction. ${ }^{6,7}$ It was mainly attributed to an early impairment of microvascular function in the presence of angiographically undetectable coronary atherosclerosis or to a longstanding adaptation to the increased load in remote regions with structural remodeling of the coronary vasculature. 6,7 Other studies have described an impairment of vasomotor tone of the angiographically normal coronary artery and remote CAD only in patients with coronary risk factors. ${ }^{8}$

In our series, all patients with angiographically normal LAD, remote $\mathrm{CAD}$, and no myocardial infarction had a CFR in the LAD within the range of the control group (Figure 1 and Table 1), which was also independent of risk factors (see confidence intervals in Figure 1) and number of vessels with disease.

We recognize 4 main limitations of our study. (1) The control group consisted of subjects with angiographically normal coronary arteries who for some reason underwent diagnostic coronary angiography. Of note, the CFR of $3.08 \pm 0.61$ of this group was similar to that reported by Kern et $\mathrm{al}^{25}(2.81 \pm 0.61)$ and Wieneke et $\mathrm{al}^{26}$ 


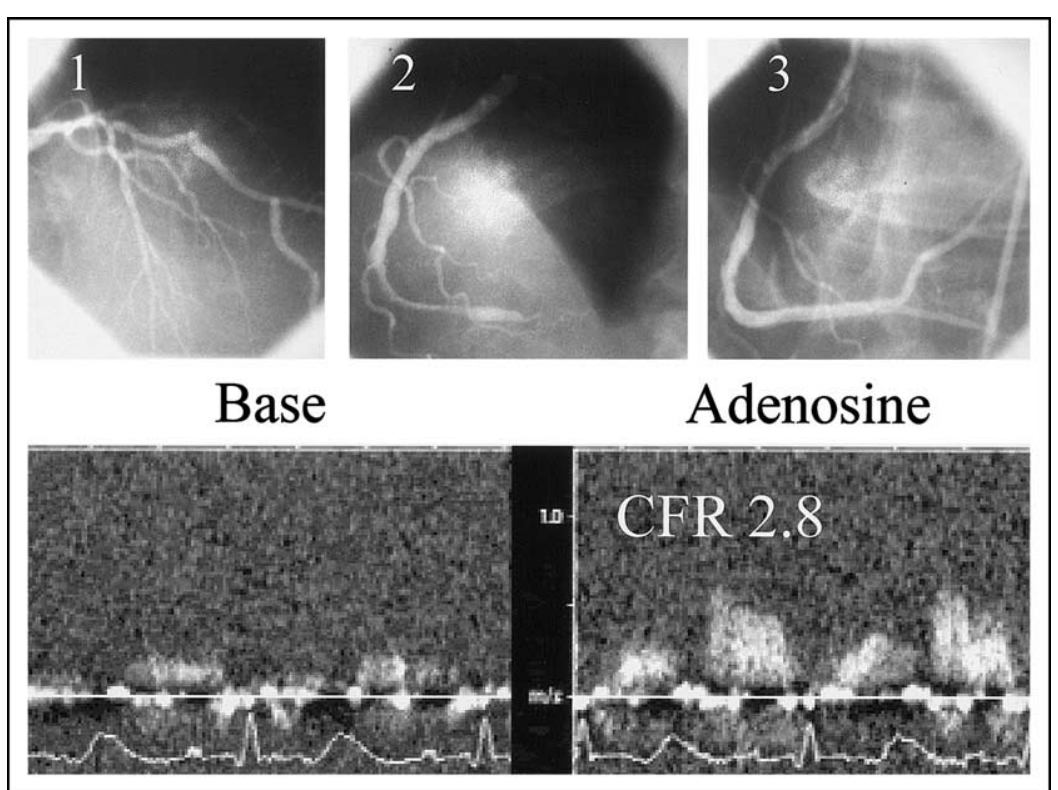

FIGURE 4. (Top) Coronary angiography of a patient in group 2C (angiographically normal LAD coronary artery and revascularized remote acute myocardial infarction) shows (1) absence of luminal narrowing of the LAD coronary artery, (2) distal occlusion of the right coronary artery, and (3) reopening of the right coronary artery by primary percutaneous transluminal coronary angioplasty and stenting. (Bottom) CFR of the LAD coronary artery, measured by transthoracic Doppler ultrasound 2 days after reopening and stenting of the right coronary artery, was 2.8, within the range of the control group.

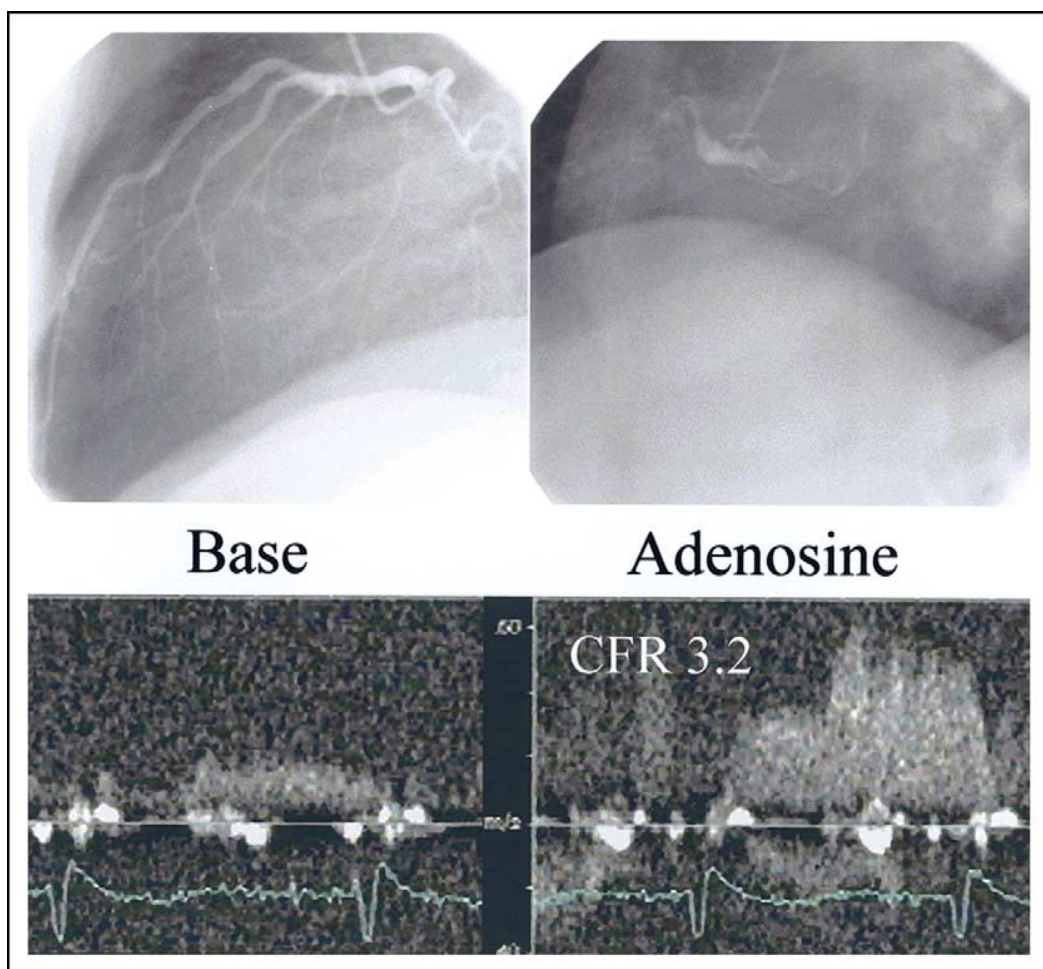

FIGURE 5. (Top) Coronary angiography of a patient in group 2D (angiographically normal LAD coronary artery and non-revascularized remote myocardial infarction) shows absence of luminal narrowing of the LAD coronary artery and a proximally occluded right coronary artery. (Bottom) CFR of the LAD coronary artery, measured by transthoracic Doppler ultrasound, shows a CFR of 3.2, within the range of the control group.
$(3.0 \pm 0.8)$ who used intracoronary Doppler ultrasound in subjects without angiographically detectable CAD and who were similar ages. CFRs of 4.07 \pm 0.98 and $3.95 \pm 0.68$ have been found by positron emission tomography in healthy volunteers with low risk of CAD, but these series included younger subjects. 6,27 Therefore, it seems that advancing age more than subclinical angiographically undetectable atherosclerosis may affect CFR. ${ }^{26,28}$ (2) Risk factors did not significantly affect our results, based on standard cut-off values. However, extremely high levels of cholesterol or other risk factors may play a role. (3) This is a single-center study that requires confirmation by data from other laboratories. (4) CFR was measured only in the LAD territory. Recent data have shown that imaging of the posterior descending coronary artery, regardless of its origin from the right or circumflex artery, is feasible. ${ }^{29,30}$

In conclusion, focal factors in each territory are responsible for CFR, and impaired CFR in 1 region is not a general phenomenon of the coronary circulation.

1. Uren NG, Crake T, Lefroy DC, de Silva R, Davies GJ, Maseri A. Reduced coronary vasodilator function in infarcted and normal myocardium after myocardial infarction. N Engl J Med 1994;331:222-227.

2. Heras M, Sanz G, Roig E, Perez-Villa F, Recasens L, Serra A, Betriu A. Endothelial dysfunction of the noninfarct related, angiographically normal, coronary artery in patients with an acute myocardial infarction. Eur Heart J 1996;17:715-720.

3. Daher E, Dione DP, Heller EN, Holahan J, DeMan P, Shen M, Hu J, Sinusas AJ. Acute ischemic dysfunction alters coronary flow reserve in remote nonischemic regions: potential mechanical etiology identified in an acute canine model. J Nucl Cardiol 2000;7:112-122.

4. Gibson CM, Ryan KA, Murphy SA, Mesley R, Marble SJ, Giugliano RP, Cannon CP, Antman EM, Braunwald E. Impaired coronary blood flow in nonculprit arteries in the setting of acute myocardial infarction. J Am Coll Cardiol 1999;34:974-982.

5. French JK, Straznicky IT, Webber BJ, Aylward PE, Frey MJ, Adgey AA, Williams BF, McLaughlin SC, White HD, for the HERO-1 Investigators. Angiographic frame counts 90 minutes after streptokinase predict left ventricular function at 48 hours following myocardial infarction. Heart 1999;81:128-133.

6. Uren NG, Marraccini P, Gistri R, de Silva R, Camici PG. Altered coronary vasodilator reserve and metabolism in myocardium subtended by normal arteries in patients with coronary artery disease. J Am Coll Cardiol 1993;22: $650-658$.

7. Sambuceti G, Marzullo O, Giorgetti A, Neglia D, Marzilli M, Salvadori P, L'Abbate A, Parodi O. Global alteration in perfusion response to increasing oxygen consumption in patients with single vessel coronary artery disease. Circulation 1994;90:1696-1705.

8. Fujiwara M, Tamura T, Yoshida K, Nakagawa K, Nakao M, Yamanouchi M, Shikama N, Himi T, Masuda $\mathrm{Y}$. Coronary flow reserve in angiographically normal coronary arteries with one-vessel coronary artery disease without traditional risk factors. Eur Heart J 2001;22:479487. 
9. Voci P, Testa G, Plaustro G, Campa PP, Marino B. Studio del flusso coronarico con ecocardiografia transtoracica ad alta risoluzione e Doppler non direzionale. Cardiologia 1997;42:849-853.

10. Voci P, Testa G, Plaustro G, Caretta Q. Coronary Doppler intensity changes during handgrip: a new method to detect coronary vasomotor tone in coronary artery disease. J Am Coll Cardiol 1999;34:428-434.

11. Voci P, Mariano E, Pizzuto F, Puddu PE, Romeo F. Coronary recanalization in anterior myocardial infarction. The open perforator hypothesis. J Am Coll Cardiol 2002;40:1205-1213.

12. Hozumi T, Yoshida K, Ogata Y, Akasaka T, Asami Y, Takagi T, Morioka S Noninvasive assessment of significant left anterior descending coronary artery stenosis by coronary flow velocity reserve with transthoracic color Doppler echocardiography. Circulation 1998;97:1557-1562.

13. Hozumi T, Yoshida K, Akasaka T, Asami Y, Ogata Y, Takagi T, Kaji S, Kawamoto T, Ueda Y, Morioka S. Noninvasive assessment of coronary flow velocity and coronary flow velocity reserve in the left anterior descending coronary artery by Doppler echocardiography. J Am Coll Cardiol 1998;32:12511259 .

14. Caiati C, Montaldo C, Zedda N, Bina A, Iliceto S. New noninvasive method for coronary flow reserve assessment. Contrast-enhanced transthoracic second harmonic echo Doppler. Circulation 1999;99:771-778.

15. Voci P, Pizzuto F, Mariano E, Puddu PE, Sardella G, Romeo F. Coronary flow reserve measured by transthoracic coronary Doppler ultrasound accurately detects severe left anterior descending coronary artery stenosis. Am J Cardiol 2003;92:1320-1324.

16. Pizzuto F, Voci P, Mariano E, Puddu PE, Sardella G, Nigri A. Assessment of flow velocity reserve by transthoracic Doppler echocardiography and venous adenosine infusion before and after left anterior descending coronary artery stenting. J Am Coll Cardiol 2001;38:155-162.

17. Pizzuto F, Voci P, Mariano E, Puddu PE, Chiavari PA, Romeo F. Noninvasive coronary flow reserve assessed by transthoracic coronary Doppler ultrasound in patients with a left anterior descending coronary artery stent. Am J Cardiol 2003;91:522-526.

18. Schiller N, Shah P, Crawford M, De Maria A, Devereux R, Feigenbaum H, Gutgesell R, Reichek N, Sahn D, Schnittger I, et al, for the American Society of Echocardiography Committee of Standards, Subcommittee on Quantification of 2-dimensional Echocardiograms. Recommendation for quantification of the left ventricle by 2-dimensional echocardiography. J Am Soc Echocardiogr 1989;5: $358-367$.

19. Bergmann SR, Herrero P, Markham P, et al. Noninvasive quantification of myocardial blood flow in human subjects with ${ }^{15} \mathrm{O}$-labeled water and positron emission tomography. J Am Coll Cardiol 1989;14:639-652.

20. Reis ES, Holubkov R, Lee JS, Sharaf B, Reichek N, Rogers WJ, Walsh EG, Fuisz AR, Kerensky R, Detre KM, et al. Coronary flow velocity response to adenosine characterizes coronary microvascular function in women with chest pain and no obstructive coronary disease: results from the pilot phase of Women's Ischemia Syndrome Evaluation (WISE) Study. $J$ Am Coll Cardiol 1999;33:1469-1475.

21. Lepper W, Hoffmann R, Kamp O, Franke A, de Cock CC, Kuhl HP, Sierswerda G, vom Dahl J, Janssens U, Voci P, et al. Assessment of myocardial reperfusion by intravenous myocardial contrast echocardiography and coronary flow reserve after primary percutaneous transluminal coronary angioplasty in patients with acute myocardial infarction. Circulation 2000;101:2368-2374.

22. Neumann FJ, Kosa I, Dickfeld T, Blasini R, Gawaz M, Hausleiter J, Schwaiger M, Schömig A. Recovery of myocardial perfusion in acute myocardial infarction after successful balloon angioplasty and stent placement in the infarctrelated coronary artery. J Am Coll Cardiol 1997;30:1270-1276.

23. Sicari R, Picano E, Landi P, Pingitore A, Bigi R, Coletta C, Heyman J, Casazza F, Previtali M, Mathias W, et al, on the behalf of the EDIC Study. Prognostic value of dobutamine-atropine stress echocardiography early after acute myocardial infarction. J Am Coll Cardiol 1997;29:254-260.

24. Gregorini L, Marco J, Kozakova M, Palombo C, Anguissola GB, Marco I, Bernies M, Cassagneau B, Distante A, Bossi IM, et al. Alpha-adrenergic blockade improves recovery of myocardial perfusion and function after coronary stenting in patients with acute myocardial infarction. Circulation 1999;99:482-490.

25. Kern MJ, Bach RG, Mechem CJ, Caracciolo EA, Aguirre FV, Miller LW, Donhoue TJ. Variations in normal coronary vasodilatory reserve stratified by artery, gender, heart transplantation and coronary artery disease. J Am Coll Cardiol 1996;28:1154-1160.

26. Wieneke H, Haude M, Ge J, Altmann C, Kaiser S, Baumgart D, von Birgelen C, Welge D, Erbel R. Corrected coronary flow velocity reserve: a new concept for assessing coronary perfusion. J Am Coll Cardiol 2000;35:1713-1720.

27. Kubo S, Tadamura E, Toyoda H, Malcero M, Mukai T, Magata Y, Kitano H, lida $\mathrm{H}$, Tamaki N, Konishi J. Comparison of myocardial blood flow during adenosine triphosphate and dobutamine infusion and after dipyridamole administration in normal men. Circulation 2002;106:II-618-II-619.

28. Czernin J, Müller P, Chan S, Brunken RC, Porenta G, Krivokapich J, Chen $\mathrm{K}$, Chan A, Phelps ME, Schelbert HR. Influence of age and hemodynamics on myocardial blood flow and flow reserve. Circulation 1993;88:62-69.

29. Voci P, Pizzuto F, Mariano E, Puddu PE, Chiavari PA, Romeo F. Measurement of coronary flow reserve in the anterior and posterior descending coronary arteries by transthoracic Doppler ultrasound. Am J Cardiol 2002;90:988-991. 30. Lethen H, Tries HP, Kersting S, Lambertz H. Validation of noninvasive assessment of coronary flow velocity reserve in the right coronary artery. A comparison of transthoracic echocardiographic results with intracoronary Doppler flow wire measurements. Eur Heart J 2003;24:1567-1575. 